Brazilian Journal

of Chemical

ISSN 0104-6632

Printed in Brazil

Engineering

www.scielo.br/bjce

Vol. 35, No. 03, pp. 1029-1038, July - September, 2018

dx.doi.org/10.1590/0104-6632.20180353s20170098

\title{
REVERSIBILITY OF AL-KAOLIN AND AL-HUMIC AGGREGATES MONITORED BY STABLE DIAMETER AND SIZE DISTRIBUTION
}

\author{
Rodrigo Braga Moruzzi ${ }^{1 * *}$ and Pedro Augusto Grava da Silva ${ }^{1}$ \\ ${ }^{1}$ Universidade Estadual Paulista (Unesp), Instituto de Geociências e Ciências \\ Exatas, Avenida 24-A, n 1515, C. P. 178, CEP 13506-900, Bela Vista, Rio Claro,
} São Paulo, Brazil.

(Submitted: February 20, 2017; Revised: August 15, 2017; Accepted: September 16, 2017)

\begin{abstract}
The reversibility of aggregates during flocculation was investigated. The stable diameter $(d)$ and the power law slope coefficient of the particle size distribution $(\beta)$ were applied to follow re-formation after breakage. A non-intrusive image-based technique was used for monitoring flocs. Aggregates were formed by adding alum $\left[\mathrm{Al}_{2}\left(\mathrm{SO}_{4}\right)_{3} \cdot 18 \mathrm{H}_{2} \mathrm{O}\right]$ by the sweep-coagulation mechanism to two synthetic waters, prepared from kaolin (Fluka) and humic acid (Aldrich Chemical). Velocity gradients $(G)$ varied from 20 to $120 \mathrm{~s}^{-1}$ during experiments, and the rupture occurred under controlled conditions. After rupture, the initial condition was reinstated and reversibility analyzed. Results pointed out the irreversibility of breakage for both Al-kaolin and Al-humic flocs. The stable diameter of aggregates after breakage $\left(d_{2}\right)$ varied from 157 to $132 \mu \mathrm{m}$ for Al-humic and from 233 to $123 \mu \mathrm{m}$ for Al-kaolin aggregates, using $G$ from 20 to $120 \mathrm{~s}^{-1}$. $\beta_{2}$ values varied from 1.2 to 4.6 for Al-humic and from 0.6 to 7.7 for Al-kaolin.
\end{abstract}

Keywords: Flocculation, Breakage, Image analysis.

\section{INTRODUCTION}

Coagulation and flocculation are widely applied in physical-chemical processes to enhance solid-liquid separation. Particle removal performance depends greatly upon the formation of aggregates with suitable proprieties, compatible with the separation technology (Chakraborti, 2003; Yukselen and Gregory, 2004). Particle aggregation may be necessary even for a membrane process, where fouling is an important issue (Yu et al., 2010a).

Coagulants based on hydrolyzing metal salts are commonly used in drinking water treatment for particle destabilization (Yukselen and Gregory, 2004). The dose of metal salts and $\mathrm{pH}$ define the mechanism of destabilization, where neutralization and sweep coagulation mechanisms are most expressive. Low coagulant dosages favor the coagulation mechanism of adsorption and charge neutralization, while higher dosages lead to sweep coagulation, as presented by Crittenden (2005). After coagulation, the destabilized particles can be aggregated by controlling mixing, using paddles or hydraulic devices. This process is called flocculation.

Flocculation kinetics can be described as the result of two combined and simultaneous effects: aggregation and breakup. The extension of each effect depends on mixing intensity and residence time; however, the dynamic balance between these

*Corresponding author. E-mail address: rmoruzzi@rc.unesp.br 
conjoint effects can lead to a steady-state aggregate size distribution (Argaman, 1970; Yukselen and Gregory, 2004). So, the flocculation steady-state can be understood as the equilibrium between shearinduced forces and aggregate strength. This balance leads to aggregates that have a specific characteristic, such as a stable representative size (diameter) and a determined size distribution, as reported by Li et al. (2006), Yu et al. (2010b) and Yu et al. (2015). Thus, aggregate formation and their characteristics strongly depend on the mechanism of destabilization and mixing conditions.

Nevertheless, breakage of aggregates may damage flocs after formation by increasing shear, thus changing their characteristics and affecting the whole separation process. In drinking water treatment plants, the breakage of aggregates may occur in the flocculation chamber itself, due to the inadequacy of mixing, or in the passages and entrances, i.e., channels, floodgates, apertures and orifices. Increased shear causes a rupture of aggregates to smaller sizes within a few seconds (Yukselen and Gregory, 2004).

Breakage of previously formed aggregates must be avoided as much as possible, but it is inevitable in some cases. The capacity of recovery of the previous size after breakage is called reversibility, and it depends on coagulant type, mixing intensity and residence time (Yukselen and Gregory, 2004; Yu et al., 2015). Reversibility may not occur, as a new steady-state after breakage of aggregates is expected.

Li et al. (2007) reported the irreversible nature of breakage in the case of hydrolyzing coagulants and $\mathrm{Yu}$ et al. (2010a) described the use of additional doses after rupture as an alternative to re-formation of aggregates. However, Yukselen and Gregory (2004) reported that aggregate formation, rupture and re-formation may occur several times, but the stable aggregate size is smaller after each breakage.

The use of surrogate parameters to evaluate aggregate size is common, and they have been used to report reversibility studies (Jarvis et al., 2005; Yu et al., 2010a; Wei at al., 2010; Yu et al., 2012). However, in this study we presented the direct measurement technique to follow reversibility, since it may be a useful tool for aggregation and breakage assessment (Sun et al., 2016).

In this paper, reversibility after breakage of aggregates for two water types was prompted under controlled conditions, using an image-based system to directly measure the stable diameter and the aggregate size distribution.

\section{METHODS}

\section{Waters studied and coagulation}

Two waters were prepared from stock solutions. For one, denominated type $1,30 \mathrm{mg} / \mathrm{L}$ humic acid solution (Aldrich Chemical) was used to obtain a 50 PtCoas initial condition, according to Constantino (2008). For another, denominated type 2, kaolin solution (Fluka) was prepared to obtain 25 NTU, according to Pádua (1994) and Yukselen and Gregory (2004). A Malvern Mastersizer 2000 was used to determine the size distribution of kaolin particles.

Coagulation was performed by dosing alum $\left[\mathrm{Al}_{2}\left(\mathrm{SO}_{4}\right)_{3} \cdot 18 \mathrm{H}_{2} \mathrm{O}\right]$ by a sweep-coagulation mechanism, following the recommendations described by Oliveira et al. (2015). Dosages were converted tp $\mathrm{Al}^{3+}$ units, and $1 \mathrm{mM}$ sodium hydroxide $(\mathrm{NaOH})$ was used as buffer during coagulation to control $\mathrm{pH}$. All assays were performed at room temperature $\left(20 \pm 2^{\circ} \mathrm{C}\right)$.

\section{Flocculation and reversibility of breakage assays}

Jar tests were performed for reversibility of aggregates, by means of flocculation and re-formation assays. The equipment (Ethik technology Model 218/6 $L D B)$ was coupled to a non-intrusive image-based system, as described by Oliveira et al. (2015). Images were taken with $2^{8}$ bits in monochromatic mode at 5 minute intervals at a frequency of $10 \mathrm{~Hz}$ for 10 seconds, using a Vision Research Miro EX4 camera together with a set of lenses to obtain a pixel size of $10 \mu \mathrm{m}$. Lighting was provided by a laser sheet of $20,000 \mathrm{~mW}$ and wavelength of $520 \mathrm{~nm}$, as described by Moruzzi and Reali (2010). A total of 900 images were processed using the Image Pro-Plus ${ }^{\circledR}$ software. Figure 1 presents a scheme of the experimental apparatus and one example of an image taken under the above described conditions.

A velocity gradient of $800 \mathrm{~s}^{-1}$ during 10 seconds for flash mix was used in all assays. For flocculation, the following mean velocity gradients $(G)$ were applied: $20,30,40,50,60,80,100$ and $120 \mathrm{~s}^{-1}$. $G$ values were kept constant during the first 25 minutes and, after this period, $G$ was set to $800 \mathrm{~s}^{-1}$ for 10 seconds for floc breakage. After rupture, the initial condition was set back to the initial value and kept at that level for 40 minutes, in order to evaluate reversibility. Figure 2 shows a scheme of how $G$ varied with time for the flocculation, breakage and re-formation studies. 

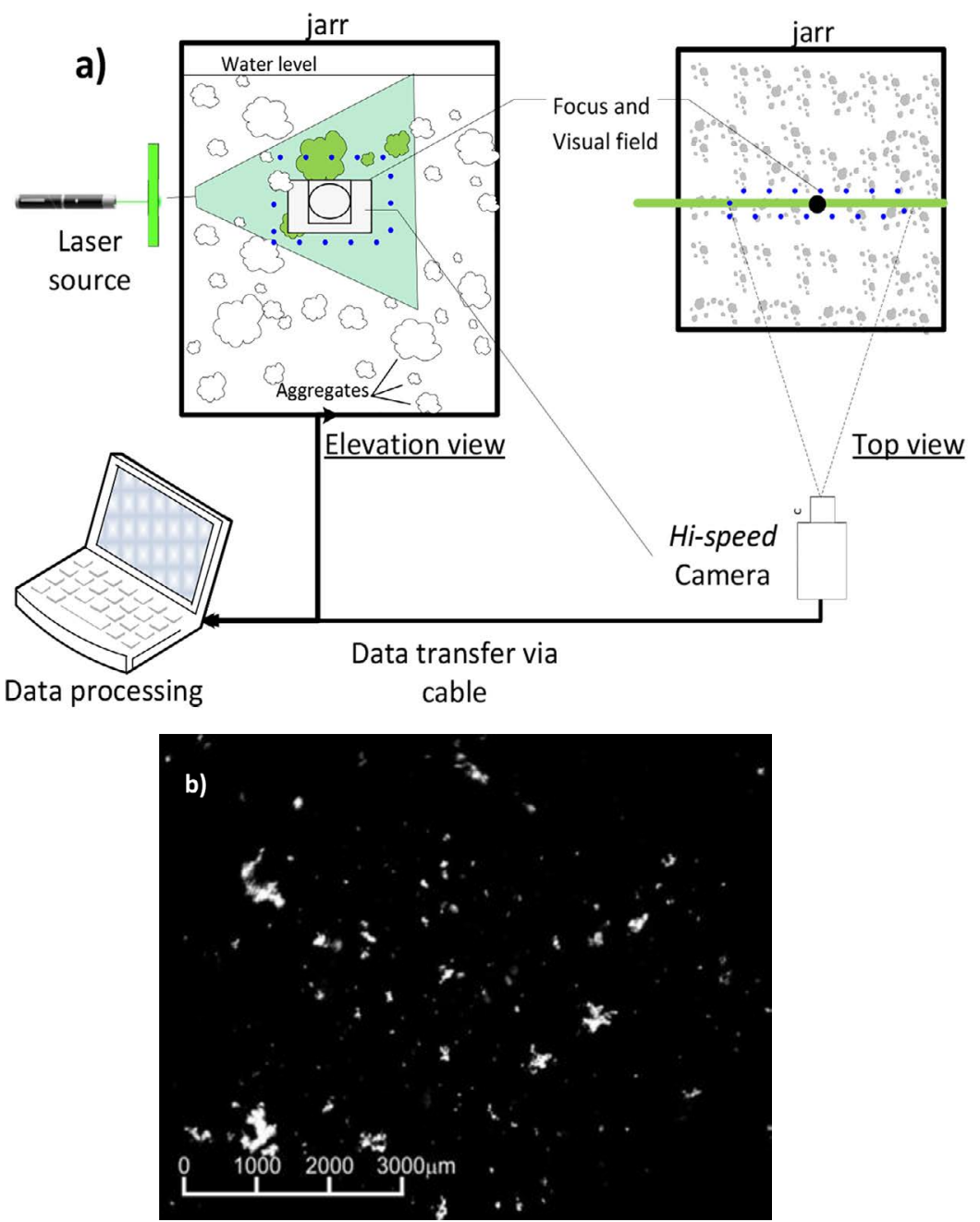

Figure 1. Scheme of the experimental apparatus (a); example of a raw image as captured (b).

\section{Determination of the stable diameter $(d)$ and power law coefficient $(\beta)$ from the aggregate size distribution}

In order to enhance precision during image processing, aggregates with diameters lower than 100 $\mu \mathrm{m}$ (10 times the pixels size) were not computed, as recommended by Chakraborti (2003), Moruzzi and Reali (2010) and Moruzzi et al. (2017).

The stable diameter $(d)$ of aggregates was determined from the plateau of temporal curves and represents the average of the aggregate characteristic length. The longest length of the encased ellipse $\left(d_{\max }\right)$ was used as the aggregate characteristic length, following Li et al. (2007) and Moruzzi et al. (2017). Thus, the value of $d_{1}$ represents the average of the $d$ values (Equation 1) or arithmetic mean during the steady state of flocculation (plateau). On the other hand, the value given by $d_{2}$ is the conjugate value of $d_{1}$ after breakage, i.e., during the re-formation stage.

$$
d=\frac{1}{n} \sum_{i=1}^{n} d_{\max }
$$

where $d$ is the stable diameter $(\mu \mathrm{m}) ; d_{\max }$ is the longest length of the encased ellipse $(\mu \mathrm{m}) ; n$ is the number of aggregates counted.

The plateau was determined from the incremental variation of mean diameter $(\Delta d)$ during flocculation. This variation tends to a narrow range, as the result of the dynamic steady state. The incremental variation was determined from Equation 2. The typical value in the plateau was then determined from the average of the diameters within $\Delta d \leq 10 \%$.

$$
\Delta d_{1,2}=\left|\frac{\left(d_{i}-d_{i-1}\right)}{d_{i}}\right|
$$

where: $\Delta d$ is the incremental variation of mean diameter; subscripts 1 and 2 are for the plateaus before and after breakage, respectively; $i$ is the time at which 


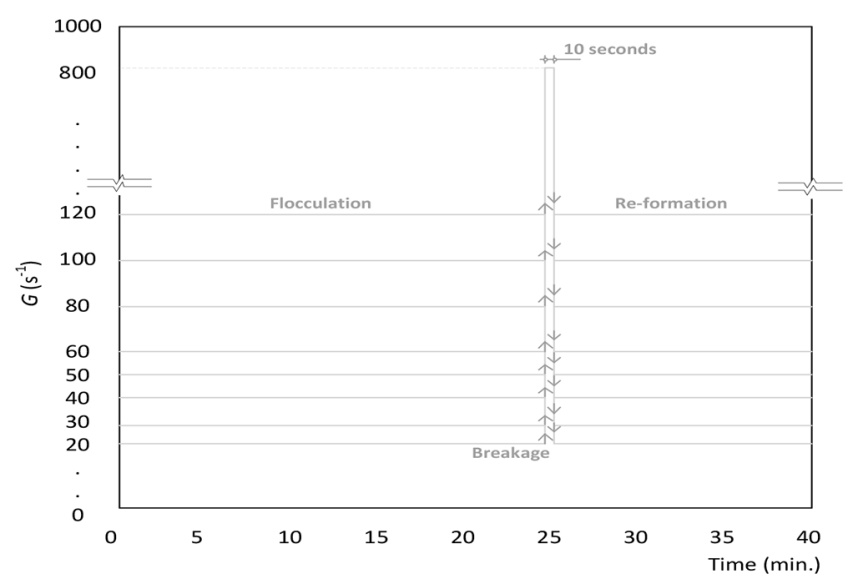

Figure 2. Scheme of $G$ variations with time for the flocculation, breakage and re-formation assays.

incremental variation is determined and $i-1$ is the previous time of $i$.

The relation between $d$ and $G$ given by Equation 3 is frequently used for indirect measurements of aggregate strength, according to Yeung and Pelton (1996). Here, it was applied for the $d$ with $G$ evaluation during flocculation and re-formation assays.

$$
d=C G^{-\gamma}
$$

where $d$ is the stable diameter; $C$ is the aggregate strength constant; $\gamma$ is the stable floc exponent; $G$ is the mean velocity gradient.

For the power law slope coefficient $(\beta)$ determination, the entire population of aggregates with different characteristic lengths $\left(d_{\max }\right)$ was classified into discrete size ranges within the interval $\mid 100-1,420$ $\mu \mathrm{m}]$ with a step of $30 \mu \mathrm{m}$. Afterwards, the $\beta$ parameter was calculated from the discrete size ranges. For each experimental set, $\beta$ was calculated by means of the best fit of a $\log$ - $\log$ plot of Equation 3. The $\log$-log plot slope $\beta$ is a measure of the relative number of particles in each size range and it was used for the analysis of particle size information, as presented by Crittenden (2005). The significance of changes of $G$ with $\beta$ values will be discussed below in the results section.

$$
\frac{d N}{d\left(d_{p}\right)}=A\left(d_{p}\right)^{-\beta}
$$

where $d N$ is the aggregate number concentration with respect to the incremental change in aggregate diameter $d\left(d_{p}\right) ; A$ is the power law density coefficient; $d_{p}$ is the aggregate diameter $(\mu \mathrm{m}) ; \beta$ is the power law slope coefficient.

Analogous to $d_{l}$, the $\beta_{1}$ values were calculated for steady state of flocculation, i.e., using the average of the $\beta$ values from the plateau. In contrast, $\beta_{2}$ is the conjugate value of $\beta_{l}$, i.e., represents the average of the $\beta$ values from the plateau after breakage, during the re-formation stage.

\section{RESULTS AND DISCUSSION}

Figure 3 shows the particle size distribution for kaolin. The results indicate a heterogeneous size range, varying from lower than $1 \mu \mathrm{m}$ up to higher than $100 \mu \mathrm{m}$ in diameter, with a median of $7.5 \mu \mathrm{m}$. The large size of kaolin was adopted as the lower limit for aggregate size recovery analysis, since particles smaller than 100 $\mu \mathrm{m}$ could represent both primary particles and small

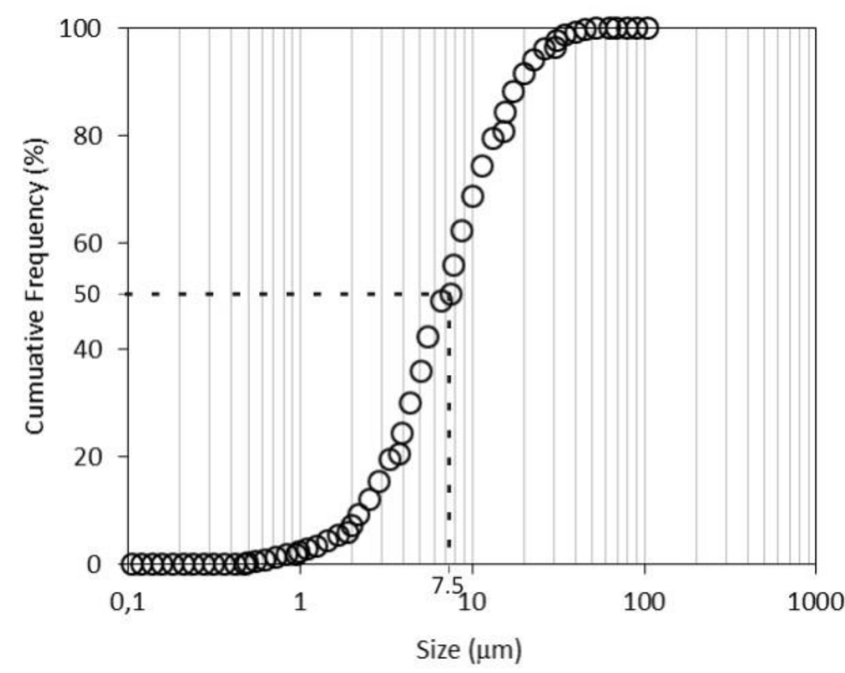

Figure 3. Cumulative primary particle size distribution for kaolin.

aggregates, thus resulting in an inaccurate region of measurement.

The type 1water was coagulated by dosing with $15 \mathrm{mg} \mathrm{Al} l^{3+} / \mathrm{L}$ at $\mathrm{pH}$ of 5.0 , while $4 \mathrm{mg} \mathrm{Al}{ }^{3+} / \mathrm{L}$ at $\mathrm{pH}$ of 7.0 were used for coagulation of the type 2 water. These were the optimum conditions, within sweepcoagulation mechanism, obtained during coagulation assays, and they were applied in all subsequent investigations.

Reversibility results regarding the aggregate stable diameter $(d)$ and power law coefficient $(\beta)$, taken from the aggregate size distribution for the two investigated waters are presented in the following items.

Figure 4 shows that the variation of $\Delta d$ from Equation 2 was smaller than $10 \%$ for the great majority of $G$ in time intervals of [10-15] and [15-20] during the flocculation. Therefore, the values of $d$ during flocculation $\left(d_{1}\right)$ and after breakage $\left(d_{2}\right)$ were taken from the interval in which $\Delta d \leq 10 \%$. 


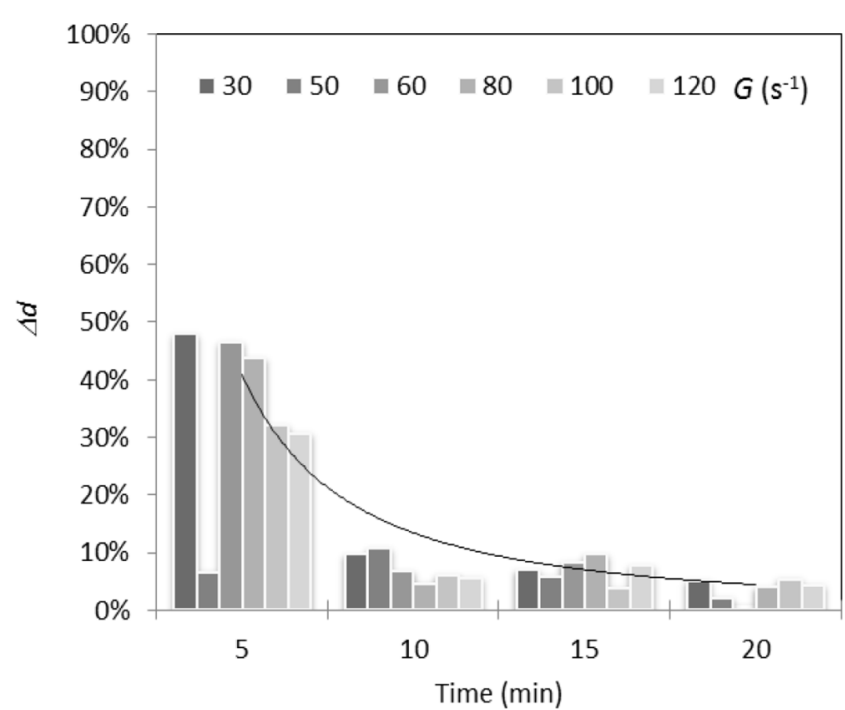

Figure 4. $\Delta d$ evolution during flocculation for different shear rates, Equation 2.

\section{Reversibility of aggregates monitored by the stable diameter $(d)$}

The stable diameter $(d)$ evolution for Al-humic and Al-kaolin aggregates in different shear rates, expressed as mean velocity gradients $(G)$, are shown in Figure 5. Aggregate formation, breakage and re-formation over time and $G$ were observed. The behavior observed in Figure 5 is quite similar to those observed by other authors using indirect measurements (Yu et al., 2015). However, the stable diameter $(d)$ can be more useful, because it assesses size instead of surrogate parameters.

Initially, the $d$ value trend was to increase until the plateau was reached, where $d_{1}$ was calculated for the interval [10-20] minutes. In some cases, a maximum aggregate size was reached, followed by a decrease before the plateau, as also described by Peng and Williams (1994). Then, the aggregates were broken at high shear rate, and $d$ values rapidly decreased to a minimum value, followed by a re-formation. So, a new stable diameter $\left(d_{2}\right)$ for the interval [30-40] minutes was calculated.

The breakage of aggregates induced by $G$ at high shear occured at 25 minutes for all investigated conditions. At this point, the majority of the $d$ values were around $150 \mu \mathrm{m}$, except for $G$ of $20 \mathrm{~s}^{-1}$ for type 2 water, where $d$ was around $250 \mu \mathrm{m}$. This behavior is difficult to explain, but it is believed that kaolin aggregates of large size would take more time than was applied to break into smaller fragments. Further, the different characteristics of primary particles can lead to different structural arrangements (Yu et al., 2015).

The values of $d_{1}$ and $d_{2}$, as well as their ratio $\left(d_{2} / d_{1}\right)$ for all shear rates and water types are summarized in Tables 1 and 2. It is clear that the $d_{2}$ values were always smaller than $d$, for all investigated conditions, as also reported by Yukselen and Gregory (2004). This ratio can be used to indirectly evaluate aggregate reversibility, where the closer to 1.0 the better the re-formation (full reversibility is reached for $d_{2} / d_{1}$ $=1$ ). However, the ratio $d_{2} / d_{1}$ is higher for high $G$, as $d_{1}$ values were smaller in these cases. Thus, high values of the ratio $d_{2} / d_{1}$ cannot be interpreted as better results, unless these values are compared at the same shear rate $(G)$. Generally, Al-kaolin aggregates seem to respond better to re-formation, when compared to Al-humic aggregates at the same $G$ value.
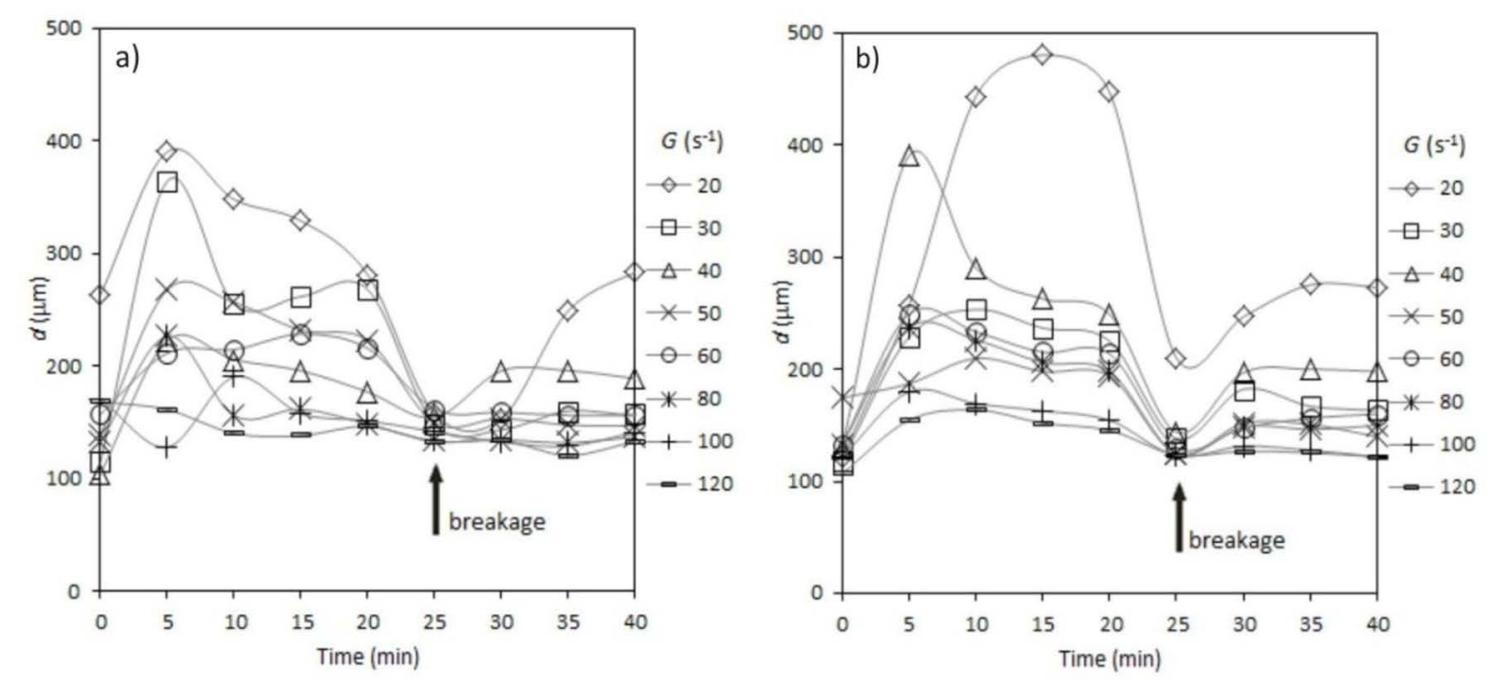

Figure 5. (a) Stable diameter $(d)$ evolution for Al-humic aggregates in different mean velocity gradients $(G)$; (b) Stable diameter $(d)$ evolution for Al-kaolin aggregates in different mean velocity gradients $(G)$. 
Table 1. Stable diameters and the power law slope coefficient $(\beta)$ for type 1 water.

\begin{tabular}{lccccc}
\hline $\boldsymbol{G}\left(\boldsymbol{s}^{-1}\right)$ & $\boldsymbol{d}_{1}(\boldsymbol{\mu m})$ & $\boldsymbol{d}_{2}(\boldsymbol{\mu} \boldsymbol{m})$ & $\boldsymbol{d}_{2} / \boldsymbol{d}_{1}$ & $\boldsymbol{\beta}_{1}$ & $\boldsymbol{\beta}_{2}$ \\
\hline 20 & $337 \pm 16$ & $157 \pm 08$ & 0.47 & $-1,61$ & $-1,24$ \\
30 & $287 \pm 14$ & $148 \pm 08$ & 0.52 & $-1,23$ & $-4,60$ \\
40 & $200 \pm 10$ & $154 \pm 08$ & 0.77 & $-2,97$ & $-3,42$ \\
50 & $244 \pm 12$ & $149 \pm 08$ & 0.61 & $-3,19$ & $-4,81$ \\
60 & $217 \pm 11$ & $161 \pm 08$ & 0.74 & $-3,01$ & $-5,11$ \\
80 & $173 \pm 09$ & $133 \pm 07$ & 0.77 & $-4,58$ & $-5,94$ \\
100 & $156 \pm 08$ & $141 \pm 07$ & 0.90 & $-4,18$ & $-5,07$ \\
120 & $146 \pm 07$ & $132 \pm 07$ & 0.90 & $-4,34$ & $-4,67$ \\
\hline
\end{tabular}

Table 2. Stable diameters and the power law slope coefficient $(\beta)$ for type 2 water.

\begin{tabular}{lccccc}
\hline $\boldsymbol{G}\left(\boldsymbol{s}^{-1}\right)$ & $\boldsymbol{d}_{1}(\boldsymbol{\mu m})$ & $\boldsymbol{d}_{2}(\boldsymbol{\mu m})$ & $\boldsymbol{d}_{1} \boldsymbol{d}_{1}$ & $\boldsymbol{\beta}_{1}$ & $\boldsymbol{\beta}_{2}$ \\
\hline 20 & $407 \pm 20$ & $233 \pm 12$ & 0.57 & $-0,37$ & $-0,56$ \\
30 & $236 \pm 12$ & $138 \pm 07$ & 0.59 & $-1,27$ & $-3,83$ \\
40 & $298 \pm 15$ & $223 \pm 06$ & 0.75 & $-2,01$ & $-4,32$ \\
50 & $197 \pm 10$ & $124 \pm 11$ & 0.63 & $-2,80$ & $-4,37$ \\
60 & $228 \pm 11$ & $222 \pm 07$ & 0.98 & $-3,58$ & $-4,56$ \\
80 & $217 \pm 08$ & $148 \pm 06$ & 0.68 & $-4,32$ & $-5,20$ \\
100 & $166 \pm 08$ & $123 \pm 06$ & 0.74 & $-4,68$ & $-6,60$ \\
120 & $154 \pm 08$ & $123 \pm 06$ & 0.80 & $-5,91$ & $-7,66$ \\
\hline
\end{tabular}

The relationship of $d$, with $G$ is shown in Figure 6 . The same behavior for both Al-humic and Al-kaolin aggregates is observed with good fit, i.e., coefficients of determination $\left(\mathrm{R}^{2}\right)$ higher than 0.79 . Futhermore, the fit parameters ( $C$ and $\gamma$ from Equation 2 ) were very close. These results may indicate that the inherent nature of the water constituents has a slight effect on aggregates, as flocs in the sweep-coagulation mechanism are incorporated within an amorphous metal hydroxide. This statement is in agreement with findings reported by Yu et al.. (2015).

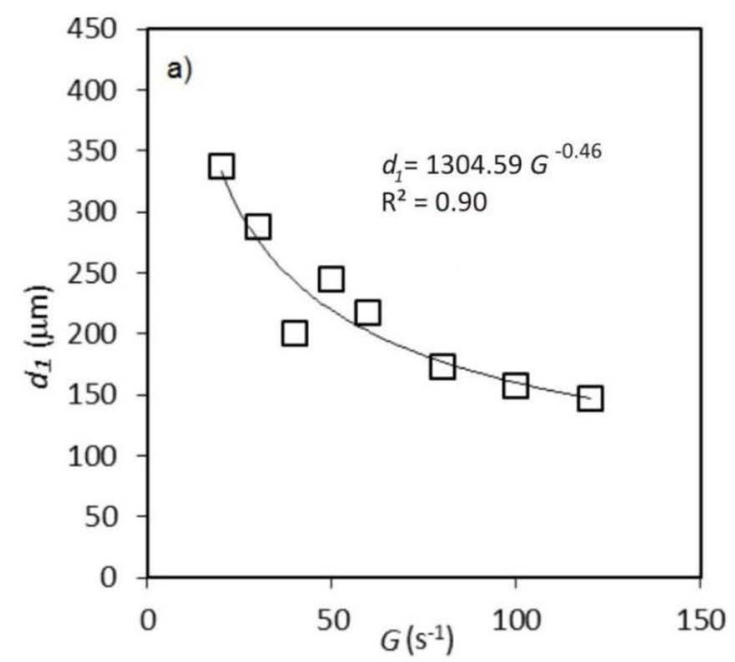

In contrast, $d_{2}$ did not respond to the $G$ variation as $d_{1}$ did. As shown in Figure 7, there was a bad fit for both cases $\left(\mathrm{R}^{2}<0.51\right)$. Further, $d_{2}$ did not follow the same behavior as $G$ was altered, showing it to be insensitive to $G$ changes. A possible explanation is that rupture damages the aggregate bonds in an irreversible way, and thus the surface activity of broken aggregates, as also observed by Wenzheng et al. (2012). Thus, the relation between shear-induced and aggregate strength was lost after breakage.

\section{Reversibility of aggregates monitored by the power law coefficient $(\beta)$}

The fits of the log-log plot of Equation 3 can be observed in Figure 8 for $G$ of 30,60 and $100 \mathrm{~s}^{-1}$ for a flocculation time $(t)$ of $40 \mathrm{~min}$. Results show different patterns as $\mathrm{G}$ values vary, following a direct relation of $\mathrm{G}$ and $\beta$ in absolute value. For $G$ of $30 \mathrm{~s}^{-1}$, a slope $\beta$ of 3.83 was found, while for $\mathrm{G}$ of 60 and $100 \mathrm{~s}^{-1}$ the slope $\beta$ values were 4.56 and 6.60 , respectively. So, lower $G$ values result in a higher relative number of aggregates in the large size ranges. Therefore, Figure 8 shows that the variation of $\mathrm{G}$ implies a $\beta$ variation, as the result of different particle size distributions.

For the same conditions of flocculation, breakage and re-formation described before, $\beta$ performance assays were carried out. Each $\beta$ value refers to the nonlinear regression of the experimental aggregate size distribution, presented by Equation 3. Figure 9 shows a compilation of experimental results carried out in exactly the same way for the two types of waters studied.

In Figure 9, values of $\beta_{1}$ indicate the power law coefficient for the flocculation stage, while $\beta_{2}$ refers to the re-formation stage, i.e., after breakage of

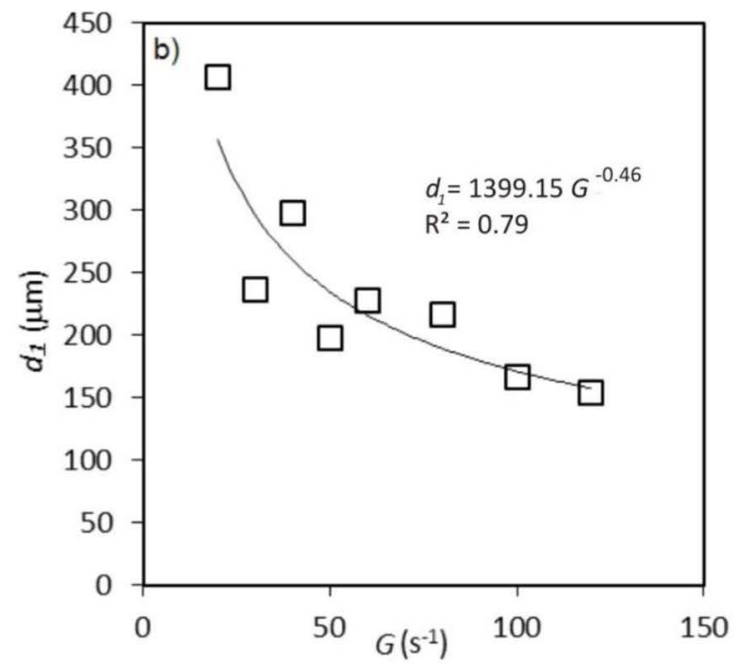

Figure 6. (a) $d_{1}$ as a function of $G$ for Al-humic aggregates; (b) $d_{1}$ as a function of $G$ for Al-kaolin aggregates. 

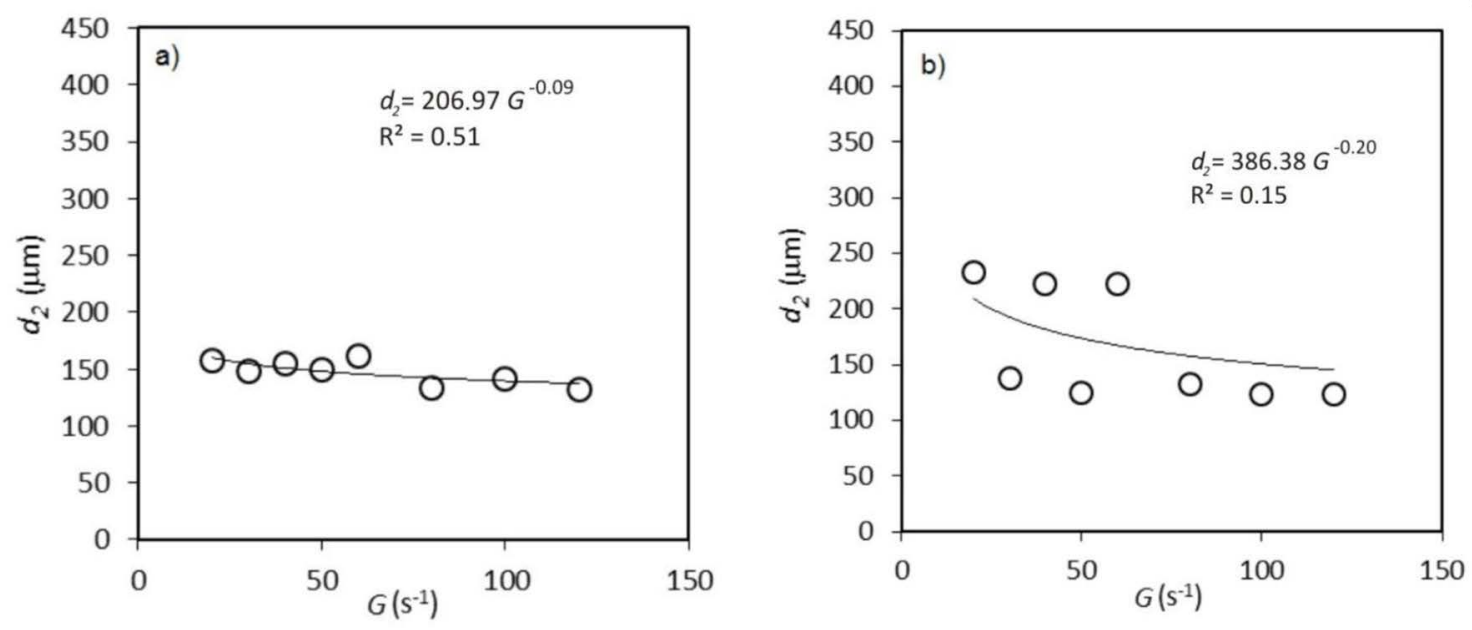

Figure 7. (a) $d_{2}$ as a function of $G$ for Al-humic aggregates; (b) $d_{2}$ as a function of $G$ for Al-kaolin aggregates.

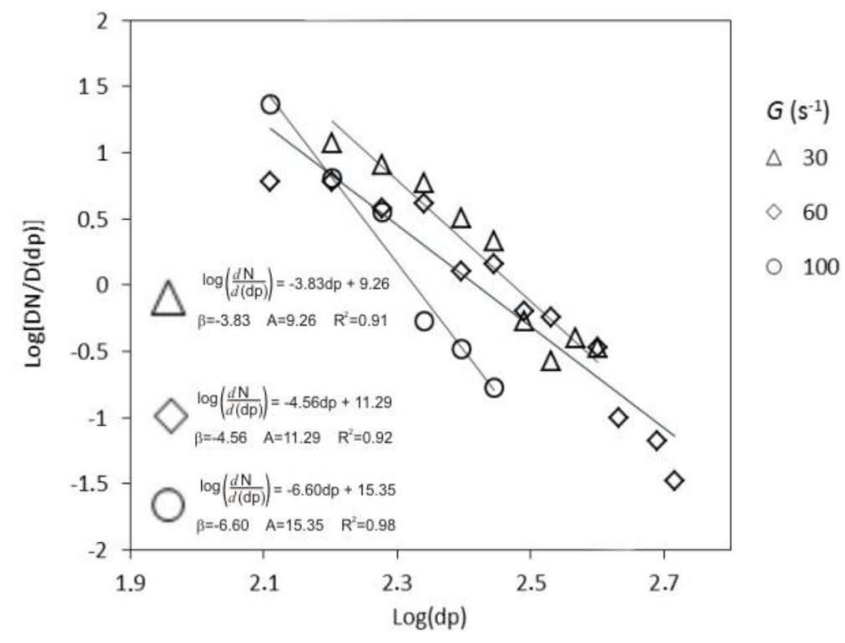

Figure 8. Typical examples of $\log$ - $\log$ plots of particle size distributions for $\beta$ calculation from Equation 3. aggregates. It is clear from Figure 9 that higher $\beta$ values were obtained from higher $G$ values, thus indicating that the aggregate size distribution was displaced to lower ranges of size when $G$ was increased. Further, lower $\beta$ values were observed for the flocculation stage $\left(\beta_{1}\right)$, showing the abundant formation of large aggregates before the breakage stage.

Figure 9 still shows that $\beta$ versus $G$ can be explained by a linear behavior, and still remains like that after breakage, i.e., as a parallel line, but in a displaced position. The displacement of $\beta$ values from $\beta_{1}$ to $\beta_{2}$ reflects a real change in the aggregate size distribution and thus in floc properties. This variation clearly shows the dramatic change in aggregate size distribution, as a consequence of the irreversible breakage of aggregates.
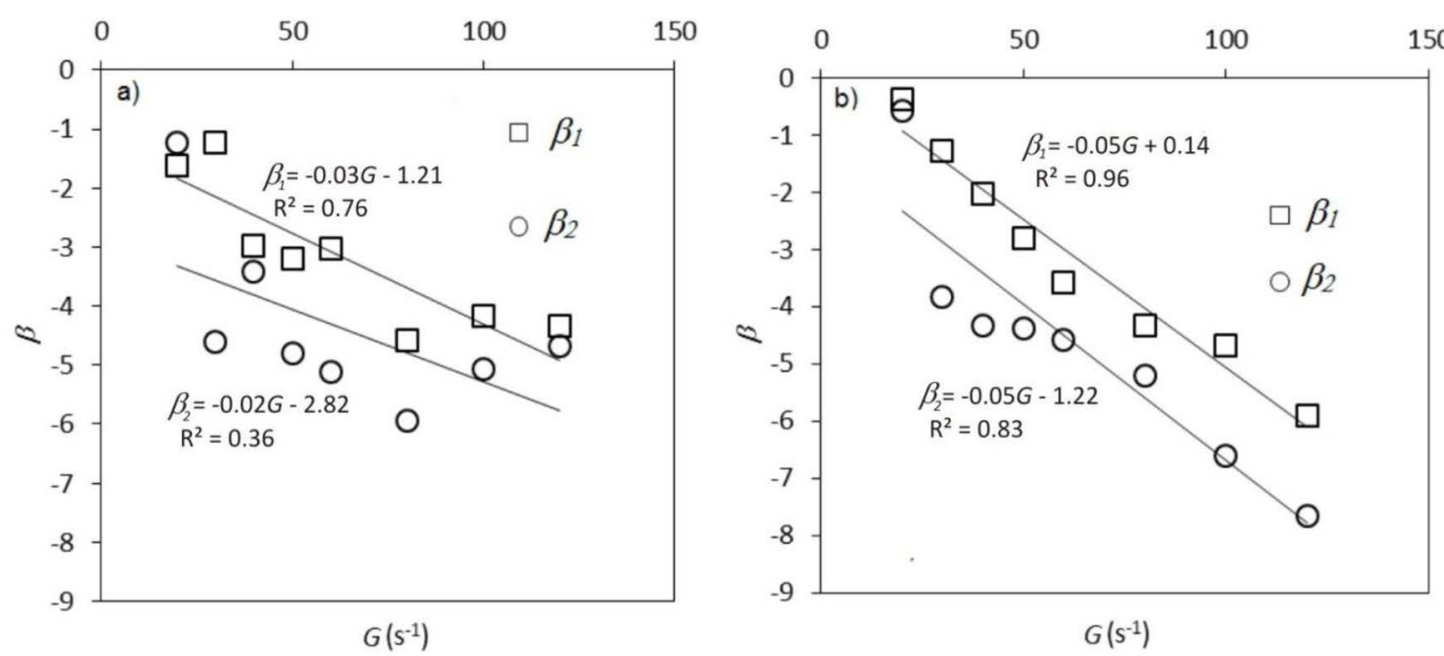

Figure 9. (a) $\beta_{1}$ and $\beta_{2}$ as a function of $G$ for Al-humic aggregates; (b) $\beta_{1}$ and $\beta_{2}$ as a function of $G$ for Al-kaolin aggregates. 
Finally, it is clear from Figure 9 that $\beta$ values vary over wider range for type 2 water (Al-kaolin) than for type 1 water (Al-humic), in agreement with the stable diameter results. However, apart from the stable diameter $(d)$ behavior, the $\beta$ values still respond to $G$ variations after rupture. Therefore, the breakage of aggregates did not result in sensitivity loss for $\beta_{2}$, despite the lower values of the coefficient of determination $\left(\mathrm{R}^{2}\right)$ obtained, compared to $\beta_{l}$.

The results presented here show very relevant aspects of the reversibility of aggregates, using both the stable diameter $(d)$ and the power law coefficient $(\beta)$ from the aggregate size distribution as flocculation and re-formation monitoring parameters. Aggregates were formed by dosing alum $\left[\mathrm{Al}_{2}\left(\mathrm{SO}_{4}\right)_{3} \cdot 18 \mathrm{H}_{2} \mathrm{O}\right]$ by the sweep-coagulation mechanism for the two synthetic waters, prepared from kaolin (Fluka) and humic acid (Aldrich Chemical). Under these conditions, and based on velocity gradients $(G)$ varying from 20 to $120 \mathrm{~s}^{-1}$, breakage of aggregates proved to be an irreversible process.

The stable diameter values of the aggregates after breakage $\left(d_{2}\right)$ were always lower than their corresponding values during flocculation $\left(d_{1}\right)$, i.e., $d_{2}$ from 157 to $132 \mu \mathrm{m}$ for Al-humic and from 233 to 123 $\mu \mathrm{m}$ for Al-kaolin aggregates, while varying $G$ from 20 to $120 \mathrm{~s}^{-1} . \beta_{2}$ values after breakage were always higher than their corresponding values, i.e., from 1.2 to 4.6 for Al-humic and from 0.6 to 7.7 for Al-kaolin.

Results also have shown that the stable diameter $(d)$ is a powerful tool to follow aggregate behavior as well as the power law coefficient $(\beta)$, taken from the aggregate size distribution. However, $\beta$ still responded to $G$ variations after breakage of aggregates while $d$ did not.

\section{CONCLUSIONS}

Based on the results presented here, it can be concluded that breakage of aggregates was an irreversible process for Al-humic and Al-kaolin waters, thus reinforcing that aggregate rupture must be avoided as much as possible.

The use of both the stable diameter $(d)$ and the power law coefficient $(\beta)$, taken from the aggregate size distribution, to follow flocculation and breakage as monitoring parameters is recommended. However, $\beta$ exhibited a sensitive response to $G$ variations and high $\mathrm{R}^{2}$ values even after breakage of theaggregates.

As may be expected, lower $d$ values and higher $\beta$ values were found for higher $G$, and vice-versa. However, the inherent nature of the water had only a slight effect on breakage of aggregates, suggesting that the amorphous precipitate of alum may strongly determine the aggregate properties.

\section{ACKNOWLEDGEMENTS}

Authors are thankful to the São Paulo Research Foundation (Fundação de Amparo à Pesquisa do Estado de São Paulo - FAPESP. Grant number 2013/25641-9) for support of this research.

\section{NOMENCLATURE}

$d \quad$ stable diameter $(\mu \mathrm{m})$

$d_{1} \quad$ the average of $d$ values during the steady state of

flocculation $(\mu \mathrm{m})$

$d_{2}$ the conjugate value of $d_{1}$, after breakage $(\mu \mathrm{m})$

$d_{\max }$ the longest length of the encased ellipse $(\mu \mathrm{m})$

$n^{\max }$ the number of aggregates counted

$C$ the aggregate strength constant $\left(\mu \mathrm{m} \cdot \mathrm{s}^{-1}\right)$

$\gamma \quad$ the stable floc exponent (dimensionless)

$G \quad$ the mean velocity gradient $\left(\mathrm{s}^{-1}\right)$

$d N$ the aggregate number concentration (dimensionless)

$d\left(d_{p}\right)$ the incremental change in aggregate diameter $(\mu \mathrm{m})$

$A$ the power law density coefficient(dimensionless)

$d_{p} \quad$ the aggregate diameter $(\mu \mathrm{m})$

$\beta^{p}$ the power law slope coefficient (dimensionless)

$\beta_{1} \quad$ the average of $\beta$ values during the steady state of flocculation (dimensionless)

$\beta_{2}$ the conjugate value of $\beta_{l}$, after breakage (dimensionless)

\section{REFERENCES}

Chakraborti, R. K.; Gardnerb, K. H.; Atkinson, J. F.; andVan Benschoten, J. E. Changes in fractal dimension during aggregation. Water Research, 37, 873-883 (2003).

Constantino, L. T. Ruptura e recrescimento de flocos em água com substâncias húmicas aquáticas coagulada com sulfato de alumínio e cloreto férrico. 164 p. Thesis (Master Degree in Hidráulica e Saneamento) - Escola de Engenharia de São Carlos da Universidade de São Paulo. São Carlos - SP (2008).

Crittenden, J. C;Trussel, R. R; Hand, D. W, Howe, K. J. and Tchobanoglous, G. Water Treatment: Principles and Design. 2nd ed.(2005)

Jarvis P., Jefferson B. andParsons, S. A. Breakage, Regrowth, and Fractal Nature of Natural Organic MatterFlocs. Environ. Sci. Technol., 39, 2307-2314 (2005) 
Li,T.Zhu, Z., Wang, D., Yao, C. and Tang, H. The strength and fractal dimension characteristics of alum-kaolin flocs. International Journal Of Mineral Processing, Beijing, Pr China, 82(1), 23-29 (2007).

Moruzzi, R. B;Oliveira, A. L andDe Julio, M. . Equipamento de Monitoramento Contínuo da Floculação (EMCF): experimentação, correlação e calibração. Revista DAE, 200, 25-36 (2015).

Moruzzi, R.B. and Reali, M.A.P. Characterization of micro-bubble size distribution and flow configuration in DAF contact zone by anonintrusive image analysis system and tracer tests. IWA Publishing, Water Science \& Technology, 61(1), 253-262 (2010).

Moruzzi, R. B. Oliveira, A. L. Conceição, F. T. Gregory, J. Campos, L. C. Fractal dimensionof large aggregates under different flocculation conditions. Science of the Total Environment, 609, 807-814 (2017).

Oliveira, A.L. de,Moreno, P., Silva, P.A.G. da,Julio, M.D. and Moruzzi, R.B. Effects of the fractal structure and size distribution of flocs on the removal of particulate matter. Desalination and Water Treatment, 57(36), 1-12 (2015).

Pádua, V.L. Metodologia para determinação dos gradientes de velocidade médios em unidades de floculação de mistura completa com câmaras em série e escoamento contínuo a partir de reatores estáticos. 165 p. São Carlos. Dissertação (Mestrado em Hidráulica e Saneamento). Escola de Engenharia de São Carlos, Universidade de São Paulo. (1994).

Peng S. J. and Williams R. A., Direct Measurement of Floc Breakage in Flowing Suspensions. Journal of Colloid and Interface Science, 166, 331-322 (1994).

Spicer, P.T., Pratsinis, S.E., Shear-induced flocculation: The evolution of floc structure and the shape of the size distribution at steady state. Water Res., 30, 1049-1056 (1996).

Sun, S., Weber-Shirk, M. and Lion, L.W., Characterization ofFlocs andFloc Size Distributions Using Image Analysis. Environmental Engineering Science. 33(1), 25 - 34 (2016).

Wei, J.C., Gao, B. Y., Yue, Q. Y. and Wang, Y. Strength and regrowth properties of polyferric-polymer dual-coagulant flocs in surface water treatment. Journal of Hazardous Materials, no. 175, p. 949954 (2010).

Wenzheng, Y., Hu, C., Liu, H. and Qu, J. Effect of dosage strategy on Al-Humicflocs growth and regrowth. Colloids and Surfaces A: Physicochemical and Engineering Aspects. 404, 106-111 (2012).

Yeung, A.K. and Pelton, R. Micromechanics: a new approach to studying the strength and breakup of flocs, Journal of Colloid and Interface Science, 184, 579-585(1996).

Yu W., Hu C., Liu H. and Qu J. Effect of dosage strategy on Al-humicflocs growth and re-growth. Colloids and Surfaces A: Physicochem. Eng. Aspects, 404, 106-111 (2012).

Yu, W., Gregory, J. and Campos, L., Breakage and Regrowth of Al-Humic Flocs - Effect of additional Coagulant Dosage. Environ. Sci. Technol, 44(16), 6371-6376 (2010a).

Yu, W., Gregory, J., Yang, Y.L., Sun, M., Liu, T. and Li, G.B., Effect of Coagulation and Applied Breakage Shear on the Regrowth of Kaolin Flocs. Environmental Engineering Science, 27(6), 483$492(2010$ b).

Yu, W., Gregory, J., Campos, L.C. and Grahan, N. Dependence of floc proprieties on coagulant type, dosing mode and nature of particles. Water Research, 68, 119-126 (2015).

Yukselen, M. A. and Gregory, J., The reversibility of flocs breakage. Internacional Journal of Mineral Processing, 73(2-4), 251-259(2004). 
